\title{
Phosphate solubilizing activity of Pseudomonas fluorescens PSM1 isolated from wheat rhizosphere
}

\author{
Anurag Yadav ${ }^{*}$, Kusum Yadav ${ }^{2}$, Anupam Vashistha ${ }^{3}$ \\ ${ }^{1}$ Department of Microbiology, College of Basic Science \& Humanities, S.D. Agricultural University, S.K. Nagar \\ (Gujarat), INDIA \\ ${ }^{2}$ Department of Biochemistry, University of Lucknow, Lucknow (Uttar Pradesh), INDIA \\ ${ }^{3}$ Department of Microbiology, Division of Life Sciences, S.B.S. (PG) Institute of Biomedical Sciences \& Research, \\ Balawala, Dehradun (Uttarakhand), INDIA \\ *Corresponding author. E-mail: anuragyadav123@gmail.com \\ Received: November 24, 2014; Revised received: December 20, 2015; Accepted: January 27, 2016
}

\begin{abstract}
A study was designed to screen and analyze the efficient phosphate solubilizing bacteria (PSBs) from wheat rhizosphere. Five biovars of Pseudomonas fluorescens (PSM1, PSM2, PSM3, PSM4 and PSM5) were isolated from wheat rhizosphere and Bacillus megaterium MTCC 8755 procured from microbial type culture collection (MTCC) Chandigarh, India. The P. fluorescens biovar PSM1 was observed to be most efficient phosphate solubilizer. Inoculation of $P$. fluorescens PSM1 and B. megaterium MTCC 8755, alone and in combination, caused the highest phosphate solubilization at $\mathrm{pH} 5$. At this $\mathrm{pH}$, maximum phosphate solubilization was observed with $B$. megaterium MTCC 8755 inoculation ( $8.2 \mathrm{mg} \mathrm{mL}^{-1}$ ) on sixth day of incubation with $P$. fluorescens PSM1 (8 mg mL on seventh day of incubation and with dual bacterial treatment $\left(10.5 \mathrm{mg} \mathrm{mL}^{-1}\right)$ on the fourth day of incubation. A correlation coefficient of linear regression equation of phosphate solubilization with $\mathrm{pH}$ indicated that $\mathrm{pH}$ value of the medium was directly correlated with tricalcium phosphate solubilization. The study will help in choosing soil $\mathrm{pH}$ specific PSB inoculant for optimizing plant growth.
\end{abstract}

Keywords: Phosphate solubilizing bacteria, Pseudomons fluorescens, Rhizosphere

\section{INTRODUCTION}

Phosphorus is an essential plant macronutrient making up to $0.2 \%$ of the plant dry weight. It is a component of key molecules like nucleic acids, phospholipids, adenosine triphosphate, and consequently plants cannot grow without a reliable supply of this nutrient. Due to excessive use of chemical fertilizers in past few decades the global problem of "over phosphatization" of soil has come under notice (Corbridge, 1985). Only 10 $-25 \%$ of $\mathrm{P}$ introduced in the form of chemical fertilizers is utilized by plants. Plants can absorb only inorganic phosphates, and concentration of inorganic phosphates in soil is very low because most of the phosphorus in soils is present in insoluble forms. Most of the applied phosphorus transforms into insoluble hard to reach for plant forms through adsorption or precipitation. Insoluble phosphates include tricalcium-phosphate, hydroxyapatite, fluorapatite, aluminum phosphate, iron phosphate, bone meal and rock phosphates. It has been estimated that there is almost 40 million tons of phosphatic rock deposit in India (Roychoudhury and Kaushik, 1989) and this material can be used as a cheap source of phosphate fertilizer for crop production.

Rhizosphere is a crucial zone for screening efficient phosphate solubilizing bacteria (PSBs). Plant growth promoting rhizobacteria (PGPR) is one of the classes of beneficial bacteria inhabiting the rhizosphere (Kloepper et al., 1989). The effect of PGPR on plant growth can be mediated by direct mechanisms like phosphate solubilization, production of auxins, gibberellins, cytokines or by supplying biologically fixed nitrogen. Many soil microorganisms surviving in rhizosphere have the capacity to solubilize insoluble inorganic phosphate through phosphatase activity. Rhizosphere of many plants have already been screened for isolating PSBs (Krishnaveni, 2010; Maheswar and Sathiyavani, 2012; Prasanna et al., 2011) In present study, five $P$. fluorescens biovars isolated from wheat rhizosphere along with $B$. megaterium MTCC 8755 were checked for phosphate solubilizing activity at four different $\mathrm{pH}$ values.

\section{MATERIALS AND METHODS}

The biovars of $P$. fluorescens were isolated from wheat rhizosphere from Balawala region of Dehradun, India $\left(30^{\circ} 25^{\prime} 49^{\prime \prime} \mathrm{N}, 78^{\circ} 11^{\prime} 26^{\prime \prime} \mathrm{E}\right)$. The wheat plants were carefully uprooted and the soil attached to the roots was collected and serially diluted. The dilutions were spread on King's - B agar (King et al., 1954) plates, incubated for $24 \mathrm{~h}$ at $28^{\circ} \mathrm{C}$ and observed for the devel- 
opment of colonies. Bacillus megaterium MTCC 8755 was procured from Microbial Type Culture Collection (MTCC), Chandigarh, India for reference purpose.

The qualitative estimation of phosphate solubilization by bacteria was done using Pikovaskaya's agar medium (HiMedia) containing tricalcium phosphate. The bacterial cultures were point inoculated on Pikovaskaya's agar. Appearance of clear zone around bacterial colony in otherwise opaque medium (due to calcium phosphate) confirmed the solubilization process. After two days of incubation the diameter of colony, zone of clearance and solubilization index was determined by the formula mentioned below.

Where, Solubilization index $=\mathrm{A} / \mathrm{B}$

$\mathrm{A}=$ Diameter $($ colony + halo zone $)$ and $\mathrm{B}=$ Colony diameter

The bacteria were identified by the method described by Bergey's manual of determinative bacteriology (Bergey and Holt, 2000).

Quantitative estimation of liberated phosphorus from bacterial biovars was done (Subba Rao, 1982) at different $\mathrm{pH}$ values $(5,6,7$ and 8$)$. In culture medium the $\mathrm{pH}$ of 5 and 6 was maintained using sodium citrate buffer (Dawson et al., 1986) and pH 78 using sodium barbital buffer (Lundblad and Macdonald, 2010). A 10 $\mathrm{mL}$ culture containing broth was withdrawn in sterilized Eppendorf ${ }^{\circledR}$ tubes and centrifuged at $120 \mathrm{rpm}$ for $20 \mathrm{~min}$ at $4^{\circ} \mathrm{C}$. The pellet was discarded and one $\mathrm{mL}$ of supernatant was withdrawn and used for estimating free phosphorus. In a separate experiment, phosphate solubilization on Pikovskaya's broth medium (Himedia) by P. fluorescens PSM1 and B. megaterium MTCC 8755, alone and in combination, was quantitatively estimated in unbuffered medium with initial neutral pH (Prasanna et al., 2011). The final pH of the medium was recorded after eight days of treatment. All the observations were done in five replications. Regression studies were performed using Statistical Package for the Social Sciences (SPSS 15) software.

\section{RESULTS AND DISCUSSION}

Phosphate solubilization is done by monocarboxylic acids like acetic acid, formic acid, gluconic acid and glycolic acid and by tricarboxylic acids like citric acid. Some of the other uncommon acids like trans-aconitic acids, propionic, isobutyric, isovaleric, ketobutyric, itaconic, isocaproic, malonic acids (Park et al., 2010); monocarboxylic hydroxyl acids like lactic acid and succinic acid (Yoshikawa et al., 1993), carboxylic acids like 2-keto gluconic acid and maleic acid; monodicarboxylic acids like oxalic acid (Gulati et al., 2010) and dicarboxylic hydroxy acids like malic acid (Kang et al., 2012) are secreted by various phosphate solubilizing bacteria.

Microorganisms often export organic acids as anions (Netik et al., 1997). Organic acids contribute to the lowering of solution $\mathrm{pH}$ as they dissociate in a $\mathrm{pH}$ de- pendent equilibrium into their respective anion(s) and proton(s). Organic acids buffer solution $\mathrm{pH}$ and continue to dissociate as protons are consumed by the dissolution reaction (Welch et al., 2002).

All the six bacterial isolates viz., P. fluorescens PSM1, PSM2, PSM3, PSM4, PSM5 and Bacillus megaterium MTCC 8755 solubilized phosphate from Pikovskaya's medium. On the basis of solubilization index (Table 1) the best phosphate solubilizing biovar, $P$. fluorescens PSM1 along with B. megaterium MTCC 8755 was selected for further study. Similar studies have already been performed on rhizosphere of foxtail millet (Krishnaveni, 2010), rice (Prasanna et al., 2011) and groundnut (Maheswar and Sathiyavani, 2012).

Quantification of phosphate solubilization by two isolates (P. fluorescens PSM1 and B. megaterium MTCC 8755 ) along with their composite inoculation was done up to eight days in Pikovskaya's broth at $30^{\circ} \mathrm{C}$ at four pH values: $\mathrm{pH}$ 5, 6, 7 and 8 (Figs. 1-3). Level of phosphate solubilized by $B$. megaterium MTCC 8755 was found maximum $\left(8.2 \mathrm{mg} \mathrm{mL}^{-1}\right)$ at $\mathrm{pH} 5$ on sixth day of treatment and minimum $\left(2.6 \mathrm{mg} \mathrm{mL}^{-1}\right)$ with $\mathrm{pH} 8$ on eight day of treatment. With $P$. fluorescens PSM1 treatment the level of free phosphorus was maximum at $\mathrm{pH} 5\left(8 \mathrm{mg} \mathrm{mL}^{-1}\right)$ on seventh day of treatment and minimum $\left(2.6 \mathrm{mg} \mathrm{mL}^{-1}\right)$ at $\mathrm{pH} 8$ on third day of treatment. With dual bacterial treatment the free phosphorus concentration was highest $\left(10.5 \mathrm{mg} \mathrm{mL}^{-1}\right)$ with $\mathrm{pH}$ 5 on the fourth day of treatment and lowest $(2.9 \mathrm{mg}$ $\mathrm{mL}^{-1}$ ) with $\mathrm{pH} 8$ on eighth day of treatment. Similar findings have previously been reported from dual inoculation with other microorganisms (Aftab Afzal, 2008; Hassani et al., 2015; Najjar et al., 2012). The increased phosphate solubilization with dual bacterial treatment could be due to different modes of phosphate solubilization by two bacteria.

After attaining the peak of phosphate solubilization a decline in free phosphate concentration was seen with all the three inoculation treatments. Similar observation has previously been reported on Penicillium sp. GL-101 (Kang et al., 2002). This effect could be due to accumulation of secondary metabolites which might hinder the overall growth of bacteria in the medium leading to slower solubilization of phosphate or could be due to the deficiency of nutrients in culture medium (Gaind and Gaur, 1989). Phosphate solubilization by $P$. fluorescens PSM1 was comparable with $B$. megaterium MTCC 8755. Both the bacteria demonstrated maximum phosphate solubilization with $\mathrm{pH} 5$ and minimum with pH 8 (Figs. 1 and 2). This observation was in agreement with previous findings on microbial phosphate solubilization (Gaind and Gaur, 1989; Marra et al., 2015).

In a separate experiment of phosphate quantification using non-buffered medium with neutral $\mathrm{pH}$, a linear regression of dissolved phosphorus by final $\mathrm{pH}$ of the medium was observed with $B$. megaterium MTCC 8755, P. fluorescens PSM1 and co-inoculation treat- 
Table 1. Phosphate solubilization index test.

\begin{tabular}{lccc}
\hline Isolate & Colony diameter $(\mathbf{m m})$ & Halo zone diameter $(\mathbf{m m})$ & Solubilization index \\
\hline P. fluorescens PSM1 & 3.3 & 10.7 & 3.24 \\
P. fluorescens PSM2 & 3.7 & 10.1 & 2.72 \\
P. fluorescens PSM3 & 4.0 & 10.0 & 2.50 \\
P. fluorescens PSM4 & 4.1 & 10.5 & 2.56 \\
P. fluorescens PSM5 & 3.8 & 9.9 & 2.60 \\
B. megaterium MTCC 8755 & 3.9 & 9.8 & 2.51 \\
\hline
\end{tabular}

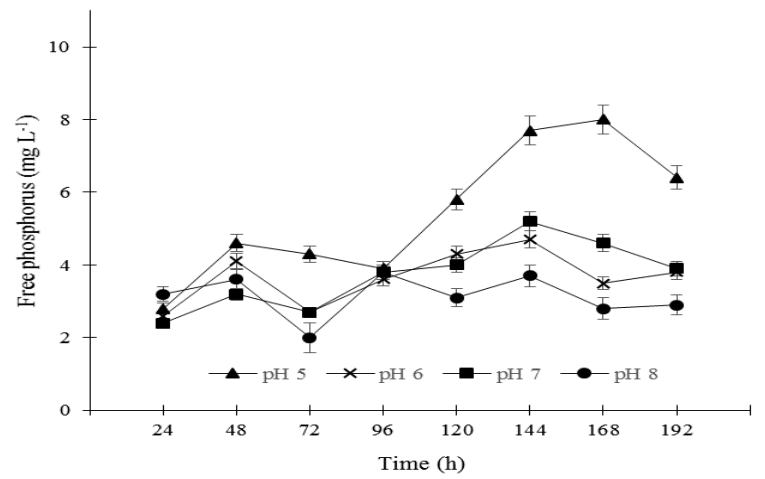

Fig. 1. Change of free phosphate concentration by P. fluorescens PSM1 at various $p H$ levels with time courses. Vertical bars represent standard error $(n=5)$.

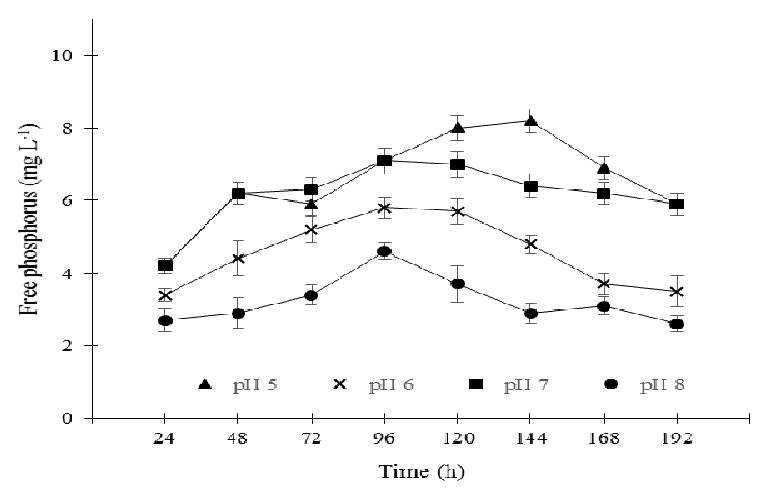

Fig. 2. Change of free phosphate concentration by $B$. megaterium MTCC 8755 at four $\mathrm{pH}$ levels with time courses. Vertical bars represent standard error $(n=5)$.

ment of B. megaterium MTCC 8755 and P. fluorescens PSM1 (Figs. 4-6). The strongest regression of phosphate solubilization $\left(\mathrm{R}^{2}\right.$ linear $\left.=0.902\right)$ with $\mathrm{pH}$ of medium was obtained with $P$. fluorescens PSM1 treatment. A sharp decline in $\mathrm{pH}$ was observed with increase in phosphate solubilization.

\section{Conclusion}

All the isolates maximally solubilized phosphate at $\mathrm{pH}$ 5 and minimally at $\mathrm{pH}$. The $P$. fluorescens PSM1 was found to be the most efficient phosphate solubilizer. A strong regression of phosphate solubilization by final $\mathrm{pH}$ of the medium was obtained in all the treatments. The findings of this experiment explore the possibility of harnessing $P$. fluorescens on commercial scale. This isolate might prove useful in agricultural practices in the soils with acidic $\mathrm{pH}$. Further study is needed in the field of bioformulation development for

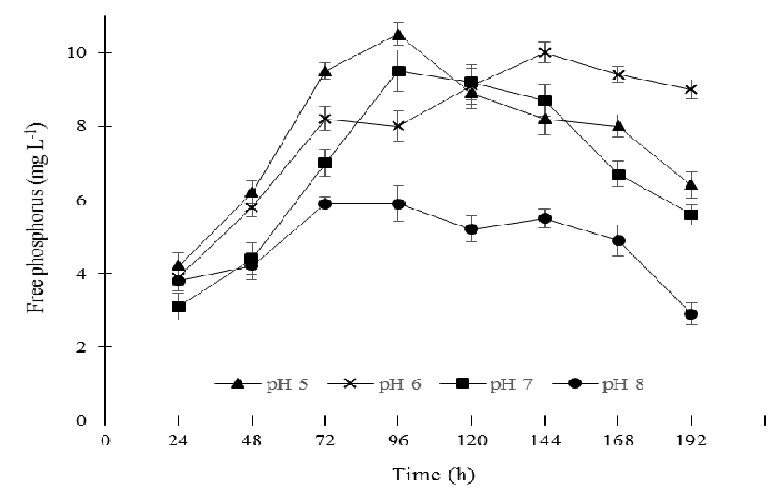

Fig. 3. Change of free phosphate concentration by composite inoculation of $P$. fluorescens PSM1 and B. megaterium MTCC 8755 at four $p H$ levels with time courses. Vertical bars represent standard error $(n=5)$.

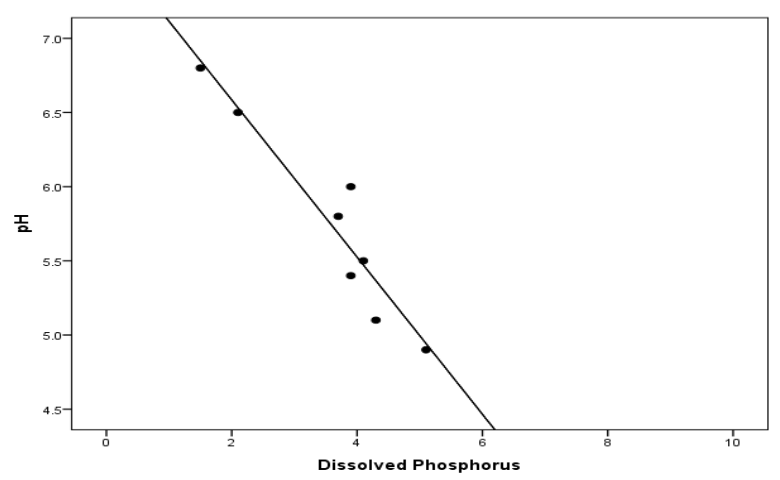

Fig. 4. Regression of dissolved phosphorus $\left(m g L^{-1}\right)$ by final $p H$ of the medium with P. fluorescens PSM1 treatment ( $Y=-$ $0.53 x+7.64 ; R^{2}$ linear $\left.=0.902\right)$. The regression coefficient is significant at $P<0.05$.

extending bacterial shelf life, enhancing bacterial-plant specificity and effect on rhizosphere ecology.

\section{ACKNOWLEDGEMENT}

The authors are thankful to Department of Microbiology, Division of Life Sciences, S.B.S. (PG) Institute of Biomedical Sciences \& Research, Balawala, Dehradun for granting permission to carry out this research.

\section{REFERENCES}

Aftab Afzal, A.B. (2008). Rhizobium and phosphate solubilizing bacteria improve the yield and phosphorus uptake in wheat (Triticum aestivum L.). Int J Agric Biol. Int. J. Agri. Biol, 10(1): 1560-8530.

Bergey, D.H. and Holt, J. (2000). Bergey's manual of determinative bacteriology, 9 ed. Williams \& Wilkins, Philadelphia. 


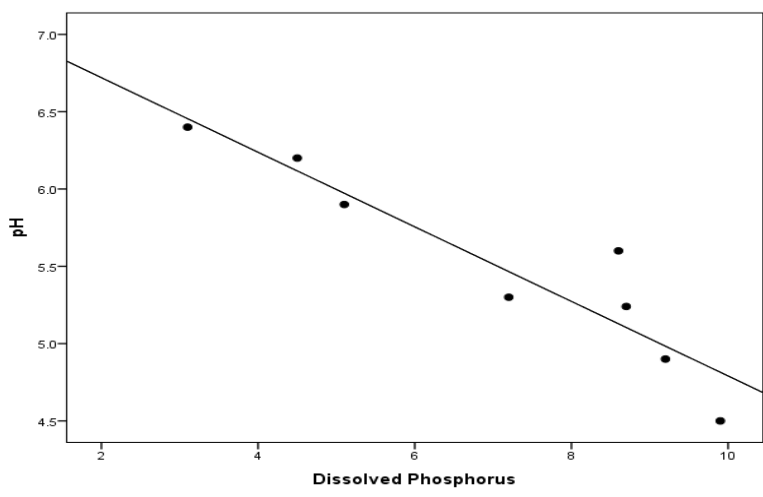

Fig. 5. Regression of dissolved phosphorus $\left(m g L^{-1}\right)$ by final $\mathrm{pH}$ of the medium with $B$. megaterium MTCC 8755 treatment $\left(Y=-0.24 x+7.2 ; R^{2}\right.$ linear $\left.=0.867\right)$. The regression coefficient is significant at $P<0.05$.

Corbridge, D.E.C. (1985). Phosphorus: an outline of its chemistry, biochemistry, and technology. Elsevier Science Publishers.

Dawson, R.M., Dawson, R.M.C., Elliot, D.C., Elliot, W.H. and Jones, K.M. (1986). Data for Biochemical Research, 3 ed. Oxford Science Publications.

Gaind, S. and Gaur, A. (1989). Effect of pH on phosphate solubilization by microbes. Current Science, 58(21): 1208-1211.

Gulati, A., Sharma, N., Vyas, P., Sood, S., Rahi, P., Pathania, V. and Prasad, R. (2010). Organic acid production and plant growth promotion as a function of phosphate solubilization by Acinetobacter rhizosphaerae strain BIHB 723 isolated from the cold deserts of the trans-Himalayas. Archives of Microbiology, 192(11): 975-983.

Hassani, F., Asgharzade, A., Ardakani, M., Hamidi, A. and Paknejad, F. (2015). Effectiveness of phosphate solubilizing bacteria inoculation for improving phosphorus absorption and root growth indices. Research Trend, p.199.

Kang, S.-M., Khan, A.L., Hamayun, M., Shinwari, Z.K., Kim, Y.-H., Joo, G.-J. and Lee, I.-J. (2012). Acinetobacter calcoaceticus ameliorated plant growth and influenced gibberellins and functional biochemicals. Pak. J. Bot, 44(1): 365-372.

Kang, S.C., Ha, C.G., Lee, T.G. and Maheshwari, D.K. (2002). Solubilization of insoluble inorganic phosphates by a soil-inhabiting fungus Fomitopsis sp. PS $102 \mathrm{Cur}$ rent Science, 82(4): 439-442.

King, E.O., Ward, M.K. and Raney, D.E. (1954). Two simple media for the demonstration of pyocyanin and fluorescin. J Lab Clin Med, 44(2): 301-307.

Kloepper, J.W., Lifshitz, R. and Zablotowicz, R.M. (1989). Free-living bacterial inocula for enhancing crop productivity. Trends in Biotechnology, 7(2): 39-44.

Krishnaveni, M.S. (2010). Studies on phosphate solubilizing bacteria (psb) in rhizosphere and non-rhizosphere soils in different varieties of foxtail millet (Setaria italica). International Journal of Agriculture and Food Science Technology, 1(1): 23-39.

Lundblad, R.L. and Macdonald, F. (2010). Handbook of Biochemistry and Molecular Biology, Fourth Edition. Taylor \& Francis.

Maheswar, N.U. and Sathiyavani, G. (2012). Solubilization

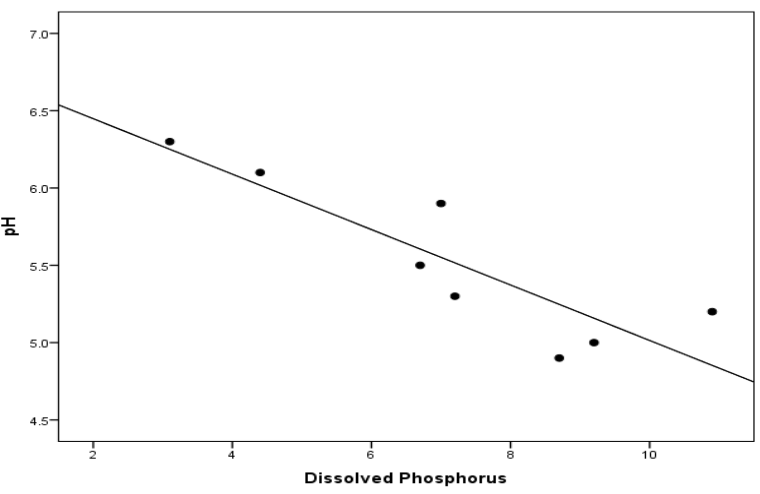

Fig. 6. Regression of dissolved phosphorus $\left(m g L^{-1}\right)$ by final $\mathrm{pH}$ of the medium by composite inoculation of B. megaterium MTCC 8755 with $P$. fluorescens PSM1 treatment ( $Y=$ $0.18 x+6.81 ; R^{2}$ linear $\left.=0.760\right)$. The regression coefficient is significant at $P<0.05$.

of phosphate by Bacillus sps, from groundnut rhizosphere (Arachis hypogaea L.) Journal of Chemical and Pharmaceutical Research, 4(8): 4007-4011.

Marra, L.M., Oliveira-Longatti, S.M.d., Soares, C.R.F.S., Lima, J.M.d., Olivares, F.L., Moreira, F.M.S., Marra, L.M., Oliveira-Longatti, S.M.d., Soares, C.R.F.S., Lima, J.M.d., Olivares, F.L. and Moreira, F.M.S. (2015). Initial $\mathrm{pH}$ of medium affects organic acids production but do not affect phosphate solubilization. Brazilian Journal of Microbiology, 46(2): 367-375.

Najjar, G., Godlinski, F., Vassilev, N. and Eichler-Löbermann, B. (2012). Dual inoculation with Pseudomonas fluorescens and arbuscular mycorrhizal fungi increases phosphorus uptake of maize and faba bean from rock phosphate. vTI Agriculture and Forestry Research: 77.

Netik, A., Torres, N.V., Riol, J.M. and Kubicek, C.P. (1997). Uptake and export of citric acid by Aspergillus niger is reciprocally regulated by manganese ions. Biochimica Et Biophysica Acta, 1326(2): 287-294.

Park, J., Bolan, N., Mallavarapu, M. and Naidu, R. (2010). Enhancing the solubility of insoluble phosphorus compounds by phosphate solubilizing bacteria, 19th World Congress of Soil Science, Soil Solutions for a Changing World Brisbane, Australia.

Prasanna, A., Deepa, V., Balakrishn, P., Deecaraman, M., Sridhar, R. and Dhandapani, P. (2011). Insoluble phosphate solubilization by bacterial strains isolated from rice rhizosphere soils from southern India. International Journal of Soil Science, 6(2): 134-141.

Roychoudhury, P. and Kaushik, B.D. (1989). Solubilization of Mussorie rock phosphate by cyanobacteria. Current Science, 58: 569-570.

Subba Rao, N.S. (1982). Advances in agricultural microbiology, London (UK), Butterworth.

Welch, S.A., Taunton, A.E. and Banfield, J.F. (2002). Effect of microorganisms and microbial metabolites on apatite dissolution. Geomicrobiology Journal, 19: 343-367.

Yoshikawa, M., Hirai, N., Wakabayashi, K., Sugizaki, H. and Iwamura, H. (1993). Succinic and lactic acids as plant growth promoting compounds produced by rhizospheric Pseudomonas putida. Can J Microbiol, 39 (12): 1150-1154. 